\title{
In silico evaluation of arrhythmia
}

\author{
Xin Zhou, Alfonso Bueno-Orovio, Blanca Rodriguez \\ Department of Computer Science, University of Oxford, Oxford, United Kingdom
}

\begin{abstract}
Iteration between computational and experimental physiology has largely contributed to expanding scientific knowledge in cardiovascular research over the last decades. In this article, we briefly review key progress in cardiac modeling for the understanding of arrhythmia, from subcellular dynamics to whole heart electrophysiology. In silico modeling has demonstrated its ability to capture the required physiological complexity, covering stochastic subcellular processes, neural and hormonal regulatory effects, and physiological variability as widely observed in vitro, ex vivo and in vivo. As a result of this unique integration of scales, arrhythmias in both congenital and acquired conditions are currently being investigated in silico, caused by channelopathies, ischemia, and drug cardiotoxicity. This witnesses a close future where in silico methods, deeply integrated with clinical data, are called to play a central role towards the development of personalized medicine.
\end{abstract}

\section{Introduction}

Since the publication of the first model of cardiac electrophysiology over five decades ago, mathematical modeling has provided increasingly more important insights into cardiac arrhythmia mechanisms. To date, mathematical models for various cell types, different species, including human, have been developed and validated using experimental recordings [1]. The field is currently pushing technological boundaries for bringing these technologies closer to their full translation to the biomedical and clinical settings. This is supported by solid scientific grounds, especially in our present understanding of modeling human physiology at multi-scales as illustrated in Figure 1 [2]. In this review, we recapitulate some of the most recent progress in the field, with an emphasis in the in silico evaluation of arrhythmia, and the assessment of potential therapeutic methods.

\section{Calcium cycling and mitochondrial impairment on arrhythmias}

Due to the fundamental role of $\mathrm{Ca}^{2+}$ signaling in the maintenance of both normal rhythm and the initiation of pro-arrhythmic conditions, refined understanding of subcellular $\mathrm{Ca}^{2+}$ homeostasis has become a priority in experimental physiology, deeply complemented by cardiac modeling. To date, modeling studies have provided crucial mechanistic interpretations for $\mathrm{Ca}^{2+}$-mediated pro-arrhythmic events such as cardiac alternans [3], early afterdepolarizations, and delayed afterdepolarizations [4][5]. Recent modeling advances are also contributing to understanding stochastic gating in $\mathrm{Ca}^{2+}$ release units (CRUs) of the sarcoplasmic reticulum [6], enabling investigations of spatially distributed CRUs and the role of subcellular $\mathrm{Ca}^{2+}$ sparks in arrhythmogenesis [7]. These studies have demonstrated a tight coupling between $\mathrm{Ca}^{2+}$ loading, CRU firing stochasticity, cell-to-cell variability, and pacing rate in the 
generation of pro-arrhythmic events [3-7]. The simulations have provided complementary evidence to wet lab experiments on the intricate interactions between subcellular $\mathrm{Ca}^{2+}$ signaling and sarcolemmal currents.

In silico modeling has also shown how regional mitochondrial impairment [8] may contribute to increased arrhythmic risk. Such research revealed how oxidative stress under ischaemic conditions can lead to non-uniform collapse of mitochondrial inner membrane potential. This then triggers the activation of sarcolemmal ATP-sensitive $\mathrm{K}^{+}$channels, leading to action potential (AP) shortening and increased propensity for re-entry due to the metabolic sink.

\section{$\beta$-adrenergic stimulation on subcellular signaling}

Pro-arrhythmic events and abnormality of calcium cycling are often triggered by external factors such as neural stimulation. As shown by Pueyo et al., phasic $\beta$-adrenergic stimulation ( $\beta \mathrm{AS}$ ) can induce oscillations in AP repolarization, which can be further amplified by mechanoelectric feedback [9]. In the recent work by Tomek et al., the effect of $\beta$ AS was modelled in postmyocardial infarction border zone, showing that $\beta A S$ can inhibit alternans generation, providing evidence on the controversial anti-arrhythmic effects of postmyocardial infarction hyperinnervation [10]. These and additional in silico studies have also greatly contributed to the current understanding of $\beta$ AS.

Growing attention is also being placed into the compartmentation and signaling of downstream ubiquitous secondary messengers, such as cAMP/PKA. Experiments in cardiac myocytes have shown that $\beta$ AS can produce compartmentalized cAMP responses [11]. Computational simulations of cAMP/PKA compartmentation have qualitatively reproduced such experimental phenomena, revealing that heterogeneity of cAMP signaling can regulate cardiac contractility upon $\beta$ AS [12]. In addition to the degradation by phosphodiesterases, simulations suggested that additional mechanisms are likely to contribute to cAMP gradients occurring in submicroscopic domains [11].

\section{Pro-arrhythmogenic genetic conditions}

Genetic mutations have been associated with many cardiac inherited conditions associated with arrhythmic risk, such as long-QT, short-QT or Brugada syndromes. Over the past decades, mathematical modeling has been increasingly used as a powerful tool to investigate the role of ion channel mutations in arrhythmia [13] (Figure 2). In the study by Hoefen et al. [14], 633 multinational subjects with 34 long-QT syndrome type 1 mutations were studied. Associations were found between transmural repolarization prolongation and the risk for cardiac events. The study provides evidence that simulated repolarization can be used to predict clinical outcomes and to improve risk stratification [14]. Efforts have also been put into the simulation of channelopathies under $\beta A S$, which can unravel the arrhythmic phenotype of ion channel mutations, resulting in repolarization abnormalities [15]. 
Recently, there is growing attention into the effect of somatic mosaicism, in which the genetic variation of an individual arises from DNA replication errors in early development. As an example of progress in this area, by incorporating early somatic mosaicism of long-QT syndrome into simulations of Purkinje fibers, Priest et al. showed that the heterogeneous expression of mutant channels can lead to 2:1 atrio-ventricular block and arrhythmia [16].

\section{Gender related risk in arrhythmia}

In the genome-scale high-throughput human study by Gaborit et al. [17], male vs female differences were revealed in the expression of key genes encoding cardiac ion channels and transporters subunits in human epicardial and endocardial tissues. Female hearts exhibit reduced expression of the $\mathrm{K}^{+}$channel subunits hERG, minK, Kir2.3, Kv1.4, KChIP2, SUR2, and Kir6.2, and lower expression of connexin43 and phospholamban compared to males. These data explained the longer female cardiac AP, and the fact that females are more prone to develop Torsades de Pointes arrhythmias under inherited and acquired long-QT comparing to males. Yang et al. [18] investigated both the role of gender-based differences in ion channel expression and the acute regulatory effects of sex hormones in human ventricular cell and tissue electrophysiology. The simulation results further evidenced mechanisms of female susceptibility to repolarization abnormalities, consistent with clinical phenotypes. In a recent study by the same group, a protein structure-based molecular docking approach was developed to explore the interaction between sex hormones, blocking drugs and hERG channels [19]. Females were predicted to have increased susceptibility to reentrant arrhythmia following acute sympathetic stimulation in the settings of long-QT syndrome.

\section{Understanding human variability in arrhythmic risk}

In cardiac electrophysiology, there are significant inter-subject differences in the electrical activity of human hearts, and even within a same region of a heart, there are cell-to-cell differences [20]. Physiological variability is difficult to investigate with experimental platforms alone, where the raw data are normally averaged [20]. Attempts of reproducing the electrophysiological variability have been made in recent years by multiple approaches, such as cell-specific dynamic parameterization [21] combined with parameter sensitivity analysis [22], and populations of models [23] [24]. The common assumption underlying the modeling of cardiac variability is that the expression level of ion channels can be regulated by many environmental factors, so the maximal conductances of ionic currents can vary to produce variable electrophysiological phenotypes [20][22].

Novel insights have been gained by using population-based modeling approaches to include physiological variability as observed experimentally or clinically. For instance, experimentally-calibrated human myocyte models have shown to reproduce the electrophysiological features of different pro-arrhythmic phenotypes in hypertrophic cardiomyopathy [25] and the role of microRNAs and nitric oxide synthases in atrial 
fibrillation [26]. Through the combination of human in vivo variability and population-based modeling, cellular mechanisms to explain different types of human cardiac alternans have been revealed [3]. Potential therapeutic treatments can also be explored for pathological conditions such as hypertrophic cardiomyopathy [25] or atrial fibrillation [27], to provide not only insights for future drug developments but to identify the molecular mechanisms underlying responders versus non-responders to therapy. This is expected to yield refined strategies towards personalized medical care, especially in high-risk groups of patients with cardiovascular disorders.

\section{In silico assessment of cardiotoxicity}

Investigations on the electrophysiological effects of drug action have always been one of the key topics of cardiac modeling. With the announcement of the Comprehensive in vitro Proarrhythmia Assay (CiPA) initiative by the USA Food and Drug Administration, academia, industry, and regulatory bodies are working to replace current testing for drug-induced proarrhythmia with in vitro and in silico assays [28]. While simple block pore models are widely used in the in silico assessment of drug safety [23][29][30], more detailed kinetic models of drug-channel interaction for sodium channels [31][32] and hERG [33][34] have been developed recently.

To achieve a more accurate evaluation of drug safety and translation to human, it is crucial to account for inter-species differences. As shown in the quantitative model comparison by O'Hara et al. [29], due to the different contribution of individual channels across species, the extrapolation from animal to human electrophysiology and drug response requires caution. In addition to the species, the aforementioned inter-subject variability within the wide population should also be considered in in silico drug safety assessments. Using a population of human ventricular models approach, Passini et al. showed that in silico models exhibited consistent and more accurate clinical risk prediction compared to animal experiments and human induced pluripotent stem cell-derived cardiomyocytes (Figure 3) [35]. An innovative study by Lancaster et al. also showed that applying machine-learning techniques on the metrics of baseline models can also predict accurate drug risk as in a small synthetic population of models [36].

\section{From arrhythmia mechanisms to personalized treatment}

Since the birth of mathematical models of cardiac electrophysiology, reproducing the arrhythmic conditions observed at tissue level has always been a focus of the field. Many pathological phenomena such as conduction block and re-entry cannot be investigated without tissue coupling effects. Recently, tissue level simulations have been conducted to predict phenotypes of short-QT syndrome [13], Brugada syndrome [37], atrial fibrillation [27] [38] [39], acute ischaemia [40][41] (Figure 4A), myocardial infarction [42], and electromechanical dynamics [43], to cite some. Potential effects of channel blockers and the effect of variability were also explored in some of these studies [37][38][40]. In addition, novel quantitative metrics have been proposed and validated through tissue modeling, to aid the identification of 
scar-related reentrant pathways in clinic [44]. Meanwhile, new approaches are being developed to improve the mathematical description of tissue structural heterogeneity [45] and to establish the link between whole-organ physiology and body surface ECGs using detailed heart-torso human anatomical models [46][47][48] (Figure 4B).

With the development of medical image processing techniques, personalized modeling based on magnetic resonance imaging (MRI) can be developed to include into consideration more detailed and specific variability of individuals, such as fiber orientation, conduction anisotropy, and spatial heterogeneities [38]. For example, in the study by Arevalo et al. [42], personalized MRI models were developed including patient-specific ventricular anatomy and the location of post-infarction scar and gray zones. After in silico reconstruction, arrhythmia inducibility in the virtual models was shown as more predictive of sudden death risk than standard clinical metrics. The results highlight the potential of cardiac modeling to assist in the clinical prevention of sudden cardiac death [42]. Similar approaches are being evaluated in other cardiac diseases, such as atrial fibrillation with the existence of atrial fibrosis [39], and to test the effects of in silico ablation [49]. Another new noninvasive approach to assist clinical diagnosis and treatment of arrhythmia is electrocardiographic imaging. After combining body surface potentials and computer tomography or MRI scans, epicardial activation and repolarization maps can be reconstructed to help identifying the arrhythmic substrate of human hearts [50][51]. Recent studies have shown that electrocardiographic imaging can identify electrical and structural substrates of arrhythmia in human hearts. These include slow discontinuous conduction and steep dispersion of repolarization in Brugada syndrome [50], as well as prolonged repolarization, non-uniform conduction and sites of premature ventricular contractions in arrhythmogenic right ventricular cardiomyopathy patients [52]. Integration of these data and computer models is expected to increase the potential of both technologies for personalized diagnosis [51].

\section{Future prospects and conclusions}

After more than half a century of history, the iteration between computational and experimental physiology has built new scientific knowledge with concomitant benefits for human health, with some recent examples shown in Table I. Mathematical modeling is now widely present at all levels of cardiac physiological research: from subcellular to whole heart levels, and from basic mechanistic research to clinical risk stratification. Together with a continuous refinement in the description of cardiac function and structure, the field is now ready to further realize its impact, including:

1) In silico screening of drug cardiotoxicity beyond acute ion channel inhibition, and in particular contractility and long-term drug exposure as urgent needs.

2) Integration of molecular dynamics into cellular models, enabling direct mechanistic insights of genetic defects from channel to cellular function, and structural-molecular interactions of drug action.

3) Extended representation of signaling pathways and ion channel trafficking, and their modulation by disease, drug action and environmental factors. 
4) Integration of the transcriptome, proteome and metabolome, as additional sources of biological data.

5) Tighter integration of medical data into the construction and validation of in silico approaches, aiming at their realization into clinical support systems.

In summary, modeling approaches can provide unique contributions to the understanding of cardiac function, promoting the development of in silico medicine in the era of big data.

\section{Acknowledgements}

Funding: The authors acknowledge support from Wellcome Trust (Senior Research Fellowship in Basic Biomedical Sciences no. 100246/Z/12/Z), British Heart Foundation (Intermediate Basic Science Research Fellowship no. FS/17/22/32644; National Centre for the Replacement, Refinement \& Reduction of Animals in Research (Infrastructure for Impact Award no. NC/P001076/1) and the CompBioMed project (European Commission grant agreement No 675451).

\section{References and recommended reading}

Papers of particular interest, published within the period of review, have been highlighted as:

- of special interest

•• of outstanding interest

[1] D. Noble, A. Garny, P.J. Noble, How the Hodgkin-Huxley equations inspired the Cardiac Physiome Project, J. Physiol. 590 (2012) 2613-2628. doi:10.1113/jphysiol.2011.224238.

[2] B. Rodriguez, A. Carusi, N. Abi-Gerges, R. Ariga, O. Britton, G. Bub, A. Bueno-Orovio, R.A.B. Burton, V. Carapella, L. Cardone-Noott, M.J. Daniels, M.R. Davies, S. Dutta, A. Ghetti, V. Grau, S. Harmer, I. Kopljar, P. Lambiase, H.R. Lu, A. Lyon, A. Minchole, A. Muszkiewicz, J. Oster, M. Paci, E. Passini, S. Severi, P. Taggart, A. Tinker, J.-P. Valentin, A. Varro, M. Wallman, X. Zhou, Human-based approaches to pharmacology and cardiology: an interdisciplinary and intersectorial workshop, Europace. 18 (2016) 1287-1298. doi:10.1093/europace/euv320.

[3] - X. Zhou, A. Bueno-Orovio, M. Orini, B. Hanson, M. Hayward, P. Taggart, P.D. Lambiase, K. Burrage, B. Rodriguez, In vivo and in silico investigation into mechanisms of frequency dependence of repolarization alternans in human ventricular cardiomyocytes, Circ. Res. 118 (2016) 266-278. doi:10.1161/CIRCRESAHA.115.307836.

This work investigated the ionic mechanisms underlying different types of cardiac alternans observed in vivo, highlighting the crucial interactions between sarcolemmal calcium currents and sarcoplasmic reticulum calcium fluxes in myocytes under the regulation of different pacing frequencies. 
[4] Z. Song, C.Y. Ko, M. Nivala, J.N. Weiss, Z. Qu, Calcium-voltage coupling in the genesis of early and delayed afterdepolarizations in cardiac myocytes, Biophys. J. 108 (2015) 1908-1921. doi:10.1016/j.bpj.2015.03.011.

[5]• Z. Song, Z. Qu, A. Karma, Stochastic initiation and termination of calcium-mediated triggered activity in cardiac myocytes, Proc. Natl. Acad. Sci. U. S. A. 114 (2017) E270-E279. doi:10.1073/pnas.1614051114.

This work presented the modeling of aberrant excitation due to spontaneous calcium release, providing a theoretical framework for interpreting complex triggered activity.

[6] X. Wang, S.H. Weinberg, Y. Hao, E.A. Sobie, G.D. Smith, Calcium homeostasis in a local/global whole cell model of permeabilized ventricular myocytes with a Langevin description of stochastic calcium release, Am. J. Physiol. Heart Circ. Physiol. 308 (2015) H510-523. doi:10.1152/ajpheart.00296.2014.

[7] E. Poláková, A. Illaste, E. Niggli, E.A. Sobie, Maximal acceleration of $\mathrm{Ca}^{2+}$ release refractoriness by $\beta$-adrenergic stimulation requires dual activation of kinases PKA and CaMKII in mouse ventricular myocytes, J. Physiol. 593 (2015) 1495-1507. doi:10.1113/jphysiol.2014.278051.

[8] L. Zhou, S. Solhjoo, B. Millare, G. Plank, M.R. Abraham, S. Cortassa, N. Trayanova, B. O’Rourke, Effects of regional mitochondrial depolarization on electrical propagation: implications for arrhythmogenesis, Circ. Arrhythm. Electrophysiol. 7 (2014) 143-151. doi:10.1161/CIRCEP.113.000600.

[9]• E. Pueyo, M. Orini, J.F. Rodríguez, P. Taggart, Interactive effect of beta-adrenergic stimulation and mechanical stretch on low-frequency oscillations of ventricular action potential duration in humans, J. Mol. Cell. Cardiol. 97 (2016) 93-105. doi:10.1016/j.yjmcc.2016.05.003.

This work highlighted the effects of both beta-adrenergic stimulation and mechano-electric feedback on the stability of action potentials.

[10]•J. Tomek, B. Rodriguez, G. Bub, J. Heijman, $\beta$-Adrenergic receptor stimulation inhibits proarrhythmic alternans in postinfarction border zone cardiomyocytes: a computational analysis, Am. J. Physiol. Heart Circ. Physiol. 313 (2017) H338-H353. doi:10.1152/ajpheart.00094.2017.

This work provided predictions and explanations for the potential anti-arrhythmic effects of hyperinnervation after myocardial infarction.

[11] P.-C. Yang, B.W. Boras, M.-T. Jeng, S.S. Docken, T.J. Lewis, A.D. McCulloch, R.D. Harvey, C.E. Clancy, A computational modeling and simulation approach to investigate mechanisms of subcellular cAMP compartmentation, PLoS Comput. Biol. 12 (2016) e1005005. doi:10.1371/journal.pcbi.1005005.

[12] N.C. Surdo, M. Berrera, A. Koschinski, M. Brescia, M.R. Machado, C. Carr, P. Wright, J. Gorelik, S. Morotti, E. Grandi, D.M. Bers, S. Pantano, M. Zaccolo, FRET biosensor uncovers cAMP nano-domains at $\beta$-adrenergic targets that dictate precise tuning of cardiac contractility, Nat. Commun. 8 (2017) 15031. doi:10.1038/ncomms15031.

[13] I. Adeniran, D.G. Whittaker, A. El Harchi, J.C. Hancox, H. Zhang, In silico investigation of a KCNQ1 mutation associated with short QT syndrome, Sci. Rep. 7 (2017) 8469. doi:10.1038/s41598-017-08367-2. 
[14] R. Hoefen, M. Reumann, I. Goldenberg, A.J. Moss, J. O-Uchi, Y. Gu, S. McNitt, W. Zareba, C. Jons, J.K. Kanters, P.G. Platonov, W. Shimizu, A.A.M. Wilde, J.J. Rice, C.M. Lopes, In silico cardiac risk assessment in patients with long QT syndrome: type 1: clinical predictability of cardiac models, J. Am. Coll. Cardiol. 60 (2012) 2182-2191. doi:10.1016/j.jacc.2012.07.053.

[15] M.A. Colman, H. Ni, B. Liang, N. Schmitt, H. Zhang, In silico assessment of genetic variation in KCNA5 reveals multiple mechanisms of human atrial arrhythmogenesis, PLOS Comput. Biol. 13 (2017) e1005587. doi:10.1371/journal.pcbi.1005587.

[16] J.R. Priest, C. Gawad, K.M. Kahlig, J.K. Yu, T. O’Hara, P.M. Boyle, S. Rajamani, M.J. Clark, S.T.K. Garcia, S. Ceresnak, J. Harris, S. Boyle, F.E. Dewey, L. Malloy-Walton, K. Dunn, M. Grove, M.V. Perez, N.F. Neff, R. Chen, K. Maeda, A. Dubin, L. Belardinelli, J. West, C. Antolik, D. Macaya, T. Quertermous, N.A. Trayanova, S.R. Quake, E.A. Ashley, Early somatic mosaicism is a rare cause of long-QT syndrome, Proc. Natl. Acad. Sci. U. S. A. 113 (2016) 11555-11560. doi:10.1073/pnas.1607187113.

[17] N. Gaborit, A. Varro, S. Le Bouter, V. Szuts, D. Escande, S. Nattel, S. Demolombe, Gender-related differences in ion-channel and transporter subunit expression in non-diseased human hearts, J. Mol. Cell. Cardiol. 49 (2010) 639-646. doi:10.1016/j.yjmcc.2010.06.005.

[18] P.-C. Yang, C.E. Clancy, In silico prediction of sex-based differences in human susceptibility to cardiac ventricular tachyarrhythmias, Front. Physiol. 3 (2012) 360. doi:10.3389/fphys.2012.00360.

[19]•P.-C. Yang, L.L. Perissinotti, F. López-Redondo, Y. Wang, K.R. DeMarco, M.-T. Jeng, I. Vorobyov, R.D. Harvey, J. Kurokawa, S.Y. Noskov, C.E. Clancy, A multiscale computational modelling approach predicts mechanisms of female sex risk in the setting of arousal-induced arrhythmias, J. Physiol. 595 (2017) 4695-4723. doi:10.1113/JP273142.

This work presented detailed modeling for the effects of hormones under sympathetic stimulation, drug block and mutations, providing mechanisms underlying female dominance of arousal-induced arrhythmias.

[20] A. Muszkiewicz, O.J. Britton, P. Gemmell, E. Passini, C. Sánchez, X. Zhou, A. Carusi, T.A. Quinn, K. Burrage, A. Bueno-Orovio, B. Rodriguez, Variability in cardiac electrophysiology: using experimentally-calibrated populations of models to move beyond the single virtual physiological human paradigm, Prog. Biophys. Mol. $\quad$ Biol. $120 \quad$ (2016) 115-127. doi:10.1016/j.pbiomolbio.2015.12.002.

[21] W. Groenendaal, F.A. Ortega, A.R. Kherlopian, A.C. Zygmunt, T. Krogh-Madsen, D.J. Christini, Cell-specific cardiac electrophysiology models, PLoS Comput. Biol. 11 (2015) e1004242. doi:10.1371/journal.pcbi.1004242.

[22]•R.A. Devenyi, F.A. Ortega, W. Groenendaal, T. Krogh-Madsen, D.J. Christini, E.A. Sobie, Differential roles of two delayed rectifier potassium currents in regulation of ventricular action potential duration and arrhythmia susceptibility, J. Physiol. 595 (2017) 2301-2317. doi:10.1113/JP273191. 
This work presented novel modeling techniques to achieve unbiased model adjustment based on information-rich dynamic clamp experiments.

[23] O.J. Britton, A. Bueno-Orovio, L. Virág, A. Varró, B. Rodriguez, The electrogenic $\mathrm{Na}^{+} / \mathrm{K}^{+}$pump is a key determinant of repolarization abnormality susceptibility in human ventricular cardiomyocytes: a population-based simulation study, Front. Physiol. 8 (2017) 278. doi:10.3389/fphys.2017.00278.

[24] J. Mayourian, T.J. Cashman, D.K. Ceholski, B.V. Johnson, D. Sachs, D.A. Kaji, S. Sahoo, J.M. Hare, R.J. Hajjar, E.A. Sobie, K.D. Costa, Experimental and computational insight into human mesenchymal stem cell paracrine signaling and heterocellular coupling effects on cardiac contractility and arrhythmogenicity, Circ. Res. $121 \quad$ (2017) 411-423. doi:10.1161/CIRCRESAHA.117.310796.

[25] E. Passini, A. Mincholé, R. Coppini, E. Cerbai, B. Rodriguez, S. Severi, A. Bueno-Orovio, Mechanisms of pro-arrhythmic abnormalities in ventricular repolarisation and anti-arrhythmic therapies in human hypertrophic cardiomyopathy, J. Mol. Cell. Cardiol. $96 \quad$ (2016) 72-81. doi:10.1016/j.yjmcc.2015.09.003.

[26] S.N. Reilly, X. Liu, R. Carnicer, A. Recalde, A. Muszkiewicz, R. Jayaram, M.C. Carena, R. Wijesurendra, M. Stefanini, N.C. Surdo, O. Lomas, C. Ratnatunga, R. Sayeed, G. Krasopoulos, T. Rajakumar, A. Bueno-Orovio, S. Verheule, T.A. Fulga, B. Rodriguez, U. Schotten, B. Casadei, Up-regulation of miR-31 in human atrial fibrillation begets the arrhythmia by depleting dystrophin and neuronal nitric oxide synthase, Sci. Transl. Med. 8 (2016) 340ra74. doi:10.1126/scitranslmed.aac4296.

[27] A. Liberos, A. Bueno-Orovio, M. Rodrigo, U. Ravens, I. Hernandez-Romero, F. Fernandez-Aviles, M.S. Guillem, B. Rodriguez, A.M. Climent, Balance between sodium and calcium currents underlying chronic atrial fibrillation termination: an in silico intersubject variability study, Heart Rhythm. 13 (2016) 2358-2365. doi:10.1016/j.hrthm.2016.08.028.

[28] G. Gintant, P.T. Sager, N. Stockbridge, Evolution of strategies to improve preclinical cardiac safety testing, Nat. Rev. Drug Discov. 15 (2016) 457-471. doi:10.1038/nrd.2015.34.

[29] T. O’Hara, Y. Rudy, Quantitative comparison of cardiac ventricular myocyte electrophysiology and response to drugs in human and nonhuman species, Am. J. Physiol. Heart Circ. Physiol. 302 (2012) H1023-1030. doi:10.1152/ajpheart.00785.2011.

[30] N. Zemzemi, B. Rodriguez, Effects of L-type calcium channel and human ether-a-go-go related gene blockers on the electrical activity of the human heart: a simulation study, Europace. 17 (2015) 326-333. doi:10.1093/europace/euu122.

[31] P.-C. Yang, N. El-Bizri, L. Romero, W.R. Giles, S. Rajamani, L. Belardinelli, C.E. Clancy, A computational model predicts adjunctive pharmacotherapy for cardiac safety via selective inhibition of the late cardiac Na current, J. Mol. Cell. Cardiol. 99 (2016) 151-161. doi:10.1016/j.yjmcc.2016.08.011.

[32] P.-C. Yang, J.D. Moreno, C.Y. Miyake, S.B. Vaughn-Behrens, M.-T. Jeng, E. 
Grandi, X.H.T. Wehrens, S.Y. Noskov, C.E. Clancy, In silico prediction of drug therapy in catecholaminergic polymorphic ventricular tachycardia, J. Physiol. 594 (2016) 567-593. doi:10.1113/JP271282.

[33] L. Romero, B. Trenor, P.-C. Yang, J. Saiz, C.E. Clancy, In silico screening of the impact of hERG channel kinetic abnormalities on channel block and susceptibility to acquired long QT syndrome, J. Mol. Cell. Cardiol. 87 (2015) 271-282.

[34]•Z. Li, S. Dutta, J. Sheng, P.N. Tran, W. Wu, K. Chang, T. Mdluli, D.G. Strauss, T. Colatsky, Improving the in silico assessment of proarrhythmia risk by combining hERG (human ether-à-go-go-related gene) channel-drug binding kinetics and multichannel pharmacology, Circ. Arrhythm. Electrophysiol. 10 (2017) e004628. doi:10.1161/CIRCEP.116.004628.

A new model of dynamic drug-hERG interactions to improve the in silico assessment of drug-induced torsades de pointes risk.

[35]••E. Passini, O.J. Britton, H.R. Lu, J. Rohrbacher, A.N. Hermans, D.J. Gallacher, R.J.H. Greig, A. Bueno-Orovio, B. Rodriguez, Human in silico drug trials demonstrate higher accuracy than animal models in predicting clinical pro-arrhythmic cardiotoxicity, Front. Physiol. $8 \quad$ (2017) 668. doi:10.3389/fphys.2017.00668.

This work demonstrated that in silico drug safety assessments can achieve higher accuracy than animal experiments, highlighting the potential of their wider applications.

[36]••M.C. Lancaster, E. Sobie, Improved prediction of drug-induced torsades de pointes through simulations of dynamics and machine learning algorithms, Clin. Pharmacol. Ther. 100 (2016) 371-379. doi:10.1002/cpt.367.

This work presented a novel computational approach for the use of machine learning techniques in anti-arrhythmic drug assessment.

[37] A. Bueno-Orovio, E.M. Cherry, S.J. Evans, F.H. Fenton, Basis for the induction of tissue-level phase-2 reentry as a repolarization disorder in the Brugada syndrome, BioMed Res. Int. 2015 (2015) 197586. doi:10.1155/2015/197586.

[38] C. Sánchez, A. Bueno-Orovio, E. Pueyo, B. Rodríguez, Atrial fibrillation dynamics and ionic block effects in six heterogeneous human 3D virtual atria with distinct repolarization dynamics, Front. Bioeng. Biotechnol. 5 (2017) 29. doi:10.3389/fbioe.2017.00029.

[39] S. Zahid, H. Cochet, P.M. Boyle, E.L. Schwarz, K.N. Whyte, E.J. Vigmond, R. Dubois, M. Hocini, M. Haïssaguerre, P. Jaïs, N.A. Trayanova, Patient-derived models link re-entrant driver localization in atrial fibrillation to fibrosis spatial pattern, Cardiovasc. Res. 110 (2016) 443-454. doi:10.1093/cvr/cvw073.

[40] S. Dutta, A. Mincholé, E. Zacur, T.A. Quinn, P. Taggart, B. Rodriguez, Early afterdepolarizations promote transmural reentry in ischemic human ventricles with reduced repolarization reserve, Prog. Biophys. Mol. Biol. 120 (2016) 236-248. doi:10.1016/j.pbiomolbio.2016.01.008.

[41] S. Dutta, A. Mincholé, T.A. Quinn, B. Rodriguez, Electrophysiological properties of computational human ventricular cell action potential models under 
acute ischemic conditions, Prog. Biophys. Mol. Biol. 129 (2017) 40-52. doi:10.1016/j.pbiomolbio.2017.02.007.

[42]••H.J. Arevalo, F. Vadakkumpadan, E. Guallar, A. Jebb, P. Malamas, K.C. Wu, N.A. Trayanova, Arrhythmia risk stratification of patients after myocardial infarction using personalized heart models, Nat. Commun. 7 (2016) 11437. doi:10.1038/ncomms11437.

This work presented a novel framework to assess the risk of sudden cardiac death in post-infarction patients based on cardiac imaging and computational modeling.

[43]•H. Ni, I. Adeniran, H. Zhang, In-silico investigations of the functional impact of KCNA5 mutations on atrial mechanical dynamics, J. Mol. Cell. Cardiol. 111 (2017) 86-95. doi:10.1016/j.yjmcc.2017.08.005.

This work presented electromechanical modeling of both gain- and loss-of-function KCNA5 mutations, revealing distinctive inotropic effects of the two groups.

[44]•Y.R. Hill, N. Child, B. Hanson, M. Wallman, R. Coronel, G. Plank, C.A. Rinaldi, J. Gill, N.P. Smith, P. Taggart, M.J. Bishop, Investigating a novel activation-repolarisation time metric to predict localised vulnerability to reentry using computational modelling, PloS One. 11 (2016) e0149342. doi:10.1371/journal.pone.0149342.

This work showed that in silico investigation can assist the identification of critical sites of reentry formation, contributing to more accurate catheter ablation therapy in the future.

[45] A. Bueno-Orovio, D. Kay, V. Grau, B. Rodriguez, K. Burrage, Fractional diffusion models of cardiac electrical propagation: role of structural heterogeneity in dispersion of repolarization, J. R. Soc. Interface. 11 (2014) 20140352. doi:10.1098/rsif.2014.0352.

[46] L. Cardone-Noott, A. Bueno-Orovio, A. Mincholé, N. Zemzemi, B. Rodriguez, Human ventricular activation sequence and the simulation of the electrocardiographic QRS complex and its variability in healthy and intraventricular block conditions, Europace. 18 (2016) iv4-iv15. doi:10.1093/europace/euw346.

[47]•N. Vandersickel, T.P. de Boer, M.A. Vos, A.V. Panfilov, Perpetuation of torsade de pointes in heterogeneous hearts: competing foci or re-entry?, J. Physiol. 594 (2016) 6865-6878. doi:10.1113/JP271728.

This work investigated the mechanisms of torsades de pointes in 2D and 3D tissue simulations, highlighting that torsades de pointes can be caused by both multiple competing foci and re-entry circuits as a result of tissue heterogeneities.

[48] A. Loewe, M.W. Krueger, F. Holmqvist, O. Dössel, G. Seemann, P.G. Platonov, Influence of the earliest right atrial activation site and its proximity to interatrial connections on P-wave morphology, Europace. 18 (2016) iv35-iv43. doi:10.1093/europace/euw349.

[49] S. Zahid, K.N. Whyte, E.L. Schwarz, R.C. Blake, P.M. Boyle, J. Chrispin, A. Prakosa, E.G. Ipek, F. Pashakhanloo, H.R. Halperin, H. Calkins, R.D. Berger, S. Nazarian, N.A. Trayanova, Feasibility of using patient-specific models and the "minimum cut" algorithm to predict optimal ablation targets for left atrial flutter, 
Heart Rhythm. 13 (2016) 1687-1698. doi:10.1016/j.hrthm.2016.04.009.

[50] J. Zhang, F. Sacher, K. Hoffmayer, T. O’Hara, M. Strom, P. Cuculich, J. Silva, D. Cooper, M. Faddis, M. Hocini, M. Haïssaguerre, M. Scheinman, Y. Rudy, Cardiac electrophysiological substrate underlying the ECG phenotype and electrogram abnormalities in Brugada syndrome patients, Circulation. 131 (2015) 1950-1959. doi:10.1161/CIRCULATIONAHA.114.013698.

[51] S. Giffard-Roisin, T. Jackson, L. Fovargue, J. Lee, H. Delingette, R. Razavi, N. Ayache, M. Sermesant, Noninvasive personalization of a cardiac electrophysiology model from body surface potential mapping, IEEE Trans. Biomed. Eng. 64 (2017) 2206-2218. doi:10.1109/TBME.2016.2629849.

[52]••C.M. Andrews, N.T. Srinivasan, S. Rosmini, H. Bulluck, M. Orini, S. Jenkins, A. Pantazis, W.J. McKenna, J.C. Moon, P.D. Lambiase, Y. Rudy, Electrical and structural substrate of arrhythmogenic right ventricular cardiomyopathy determined using noninvasive electrocardiographic imaging and late Gadolinium magnetic resonance imaging, Circ. Arrhythm. Electrophysiol. 10 (2017) pii: e005105. doi:10.1161/CIRCEP.116.005105.

This work evidenced, using electrocardiographic imaging, that patients with arrhythmogenic right ventricular cardiomyopathy can have premature ventricular contractions in both of their ventricles, suggesting potential applications for the techniques in noninvasive diagnosis and follow-up of patients. 


\section{Figure captions}

Figure 1: Experimental data from multiple scales are integrated in computational models of human cardiac electrophysiology. Reproduced from [2].

Figure 2: Effect of a KCNQ1 mutation leading to short-QT on the pseudo-ECG (A) action potentials and IKs profiles of epicardial (B), mid-myocardial (C), and endocardial (D) cells. Color-code represents wild type (WT; blue), and WT-V307L (green) and V307L (red) conditions. Reproduced from [13].

Figure 3: Simulated effect of Moxifloxacin (A), Dofetilide (B), and Flecainide (C) on a population of human ventricular cardiomyocytes leading to depolarization (green) and repolarization abnormalities (pink), from Passini et al [35].

Figure 4: Linking human whole ventricle electrophysiology to body surface ECGs. A: Simulation of a reentrant arrhythmia in the human ventricles around the acute ischemic zone with similar pattern in control (top) and for 30\% (middle) and 50\% (bottom) IKr reduction following premature excitation, from Dutta et al [40]. The limits of the border zone are marked with green lines and the direction of propagation with white arrows. B: Hemiblock of the left ventricular (LV) human posterior wall conduction system, resulted in delayed LV basal paraseptal activation, affecting the time course and position of the negative pole in the front of the torso, with the associated clinical manifestations of left posterior fascicular block (LPFB), from Cardone-Noott et al [46]. 
Table I: Combining experimental and clinical knowledge generates new insights with benefits for human health

\begin{tabular}{|c|c|c|c|}
\hline $\begin{array}{l}\text { Experimental or } \\
\text { clinical observations }\end{array}$ & $\begin{array}{l}\text { In silico modeling } \\
\text { approach }\end{array}$ & $\begin{array}{l}\text { New insights from the } \\
\text { combined approach }\end{array}$ & Ref \\
\hline $\begin{array}{l}\text { Two types of } \\
\text { repolarization } \\
\text { alternans with } \\
\text { distinct } \\
\text { rate-dependence } \\
\text { identified in patients. }\end{array}$ & $\begin{array}{l}\text { Population of human } \\
\text { ventricular cell } \\
\text { models calibrated } \\
\text { based on the in vivo } \\
\text { human variability. }\end{array}$ & $\begin{array}{l}\text { Differences in L-type } \mathrm{Ca}^{2+} \\
\text { current density are responsible } \\
\text { for the different types of } \\
\text { alternans. } \mathrm{Na}^{+} / \mathrm{Ca}^{2+} \text { exchanger } \\
\text { blockers identified as } \\
\text { therapeutic target. }\end{array}$ & 3 \\
\hline $\begin{array}{l}\text { Low frequency } \\
\text { oscillations in } \\
\text { ventricular } \\
\text { repolarization } \\
\text { identified in heart } \\
\text { failure patients. }\end{array}$ & $\begin{array}{l}\text { Human ventricular } \\
\text { model of } \\
\text { electrophysiology, } \\
\beta \text {-adrenergic } \\
\text { signaling and } \\
\text { electromechanical } \\
\text { feedback. }\end{array}$ & $\begin{array}{l}\beta \text {-adrenergic signaling and } \\
\text { phasic mechanical loading can } \\
\text { induce low-frequency } \\
\text { oscillations of repolarization. } \\
\text { Heart failure increases these } \\
\text { oscillations, leading to } \\
\text { arrhythmogenic events. }\end{array}$ & 9 \\
\hline $\begin{array}{l}\text { Female sex is a risk } \\
\text { factor for acquired } \\
\text { long-QT and arousal } \\
\text { arrhythmias. Sex } \\
\text { hormones regulate } \\
\text { cardiac ion channel } \\
\text { activity. }\end{array}$ & $\begin{array}{l}\text { Human ventricular } \\
\text { model for male and } \\
\text { female, combining } \\
\text { acute sex hormone } \\
\text { effects, ion channel } \\
\text { mutation, and } \\
\text { molecular docking. }\end{array}$ & $\begin{array}{l}\text { Acute sympathetic nervous } \\
\text { activity discharge, and } \\
\text { structural-molecular } \\
\text { interactions of oestrogens with } \\
\text { hERG mutations and blockers, } \\
\text { increase torsadogenic effects in } \\
\text { females. }\end{array}$ & 19 \\
\hline $\begin{array}{l}\text { Hypertrophic } \\
\text { cardiomyopathy ionic } \\
\text { remodeling includes } \\
\text { both increased } \\
\text { inward and reduced } \\
\text { outward currents. }\end{array}$ & $\begin{array}{l}\text { Population of human } \\
\text { ventricular cell } \\
\text { models calibrated } \\
\text { with experimental } \\
\text { data. }\end{array}$ & $\begin{array}{l}\text { Ionic mechanisms underlying } \\
\text { different phenotypes of } \\
\text { repolarization abnormalities in } \\
\text { the disease. Multichannel block } \\
\text { strategies to increase efficacy } \\
\text { without compromising } \\
\text { contractility. }\end{array}$ & 25 \\
\hline $\begin{array}{l}\text { Multiple drugs were } \\
\text { tested in HEK293 } \\
\text { cell line, stably } \\
\text { expressing the human } \\
\text { hERG1a subunit. }\end{array}$ & $\begin{array}{l}\text { Dynamic } \\
\text { hERG-binding } \\
\text { model. }\end{array}$ & $\begin{array}{l}\text { hERG channel-drug binding } \\
\text { kinetics incorporated into in } \\
\text { silico assessment of } \\
\text { proarrhythmia risk, relevant for } \\
\text { both clinical management and } \\
\text { drug development. }\end{array}$ & 34 \\
\hline $\begin{array}{l}\text { Post-infarction } \\
\text { patients are at high } \\
\text { risk of lethal } \\
\text { arrhythmias due to } \\
\text { myocardial } \\
\text { heterogeneity. }\end{array}$ & $\begin{array}{l}\text { 3D patient-specific } \\
\text { ventricular model } \\
\text { based on } \\
\text { contrast-enhanced } \\
\text { clinical MRI. }\end{array}$ & $\begin{array}{l}\text { Inducibility of arrhythmias in } \\
\text { the personalized models shown } \\
\text { as more predictive of sudden } \\
\text { death risk than standard clinical } \\
\text { metrics. }\end{array}$ & 42 \\
\hline
\end{tabular}




\begin{tabular}{|l|l|l|l|}
\hline $\begin{array}{l}\text { Exit sites in } \\
\text { scar-related reentry } \\
\text { are important targets } \\
\text { for catheter ablation, } \\
\text { but their accurate } \\
\text { location is difficult. }\end{array}$ & $\begin{array}{l}\text { 2D, 3D and } \\
\text { anatomically-detailed } \\
\text { rabbit whole } \\
\text { ventricular model. }\end{array}$ & $\begin{array}{l}\text { A new algorithm is developed } \\
\text { to identify sites susceptible to } \\
\text { reentry in order to facilitate } \\
\text { clinical catheter ablation. }\end{array}$ & 44 \\
\hline $\begin{array}{l}\text { Diagnosis and risk } \\
\text { stratification } \\
\text { challenging in } \\
\text { arrhythmogenic right } \\
\text { ventricular } \\
\text { cardiomyopathy. }\end{array}$ & $\begin{array}{l}\text { Non-invasive } \\
\text { electrocardiographic } \\
\text { imaging to } \\
\text { reconstruct } \\
\text { patient-specific } \\
\text { epicardial potentials. }\end{array}$ & $\begin{array}{l}\text { Ventricular ectopy can be } \\
\text { detected non-invasively, which } \\
\text { can contribute to the early } \\
\text { diagnosis and follow-up of } \\
\text { patients. }\end{array}$ & 52 \\
\hline
\end{tabular}

